\title{
Precipitation and Termination of Asthmatic Attack by Intense Anxiety
}

\author{
Majed Odeh ${ }^{\mathrm{a}, \mathrm{b}}$, Yana Kogan ${ }^{\mathrm{a}}$
}

\begin{abstract}
Asthma is one of the most common chronic non-communicable diseases, and characterized by airflow obstruction with variable respiratory symptoms and variable airflow limitation. Several risk factors that predispose to asthma and several triggers which are environmental factors that worsen asthma in a patient with established disease have been identified. Psychological factors can induce bronchoconstriction, and many asthmatics report worsening symptoms with stress and anxiety. We describe a patient with bronchial asthma who developed a severe asthmatic attack in response to intense anxiety. As the asthmatic attack became more severe, also the anxiety became more intense and progressed to a hysterical attack with "loss of consciousness". This was followed, almost immediately, by termination of her asthmatic attack. To the best of our knowledge, no similar case has been previously reported.
\end{abstract}

Keywords: Bronchial asthma; Anxiety; Hysteria; Psychosomatic disease

\section{Introduction}

Asthma is a disease of the airways that causes them to narrow too easily and too much in response to stimuli that have little or no effect in normal subjects. It is one of the most common chronic non-communicable diseases, and characterized by airflow obstruction with variable respiratory symptoms and variable airflow limitation. It displays a complex pathophysiology, and several risk factors that predispose to asthma and several triggers which are environmental factors that worsen asthma in a patient with established disease have been identified [13]. Abundant objective data now exist which demonstrate that psychological factors can interact with the asthmatic diathesis to worsen or ameliorate the disease process [1-4].

We describe an asthmatic woman, who during a severe

Manuscript submitted May 17, 2018, accepted June 12, 2018

aDepartment of Internal Medicine A, Bnai Zion Medical Center, and Faculty of Medicine, Technion, Haifa, Israel

${ }^{b}$ Corresponding Author: Majed Odeh, Department of Internal Medicine A, Bnai Zion Medical Center, Golomb 47, Haifa 31048, Israel.

Email: majed.odeh@b-zion.org.il

doi: https://doi.org/10.14740/jmc3092w asthmatic attack, which was precipitated by intense anxiety, developed a hysterical attack with "loss of consciousness", a complication which was followed by termination of her asthmatic attack almost immediately. To the best of our knowledge, there is no reported similar case.

\section{Case Report}

A 72-year-old woman with a history of essential hypertension for 6 years, and bronchial asthma for 3 years which developed shortly after the death of her husband, and was confirmed by respiratory function tests, was hospitalized because her asthma has become much worse despite treatment with prednisone, 40 $\mathrm{mg}$ a day, sustained-release theophylline, $300 \mathrm{mg}$ twice a day, and inhalation of terbutaline and ipratropium bromide three times a day. The worsening of her asthma began after her pulmonologist, to whom she was attached very much, informed her that he is going to travel abroad after 2 weeks for 3 months. In the day of travel she became more anxious and developed a severe asthmatic attack. Her other medications at admission included captopril $25 \mathrm{mg}$ three times a day. Other medical history was unremarkable.

Physical examination revealed an anxious patient with respiratory distress and tachypnea (36 breaths per minute), and breathing efforts were associated with cough, audible expiratory wheezing and the use of accessory muscles of respiration. Her pulse was 100 beats per minute and regular, and her blood pressure was 160/90 mm Hg. Examination of the chest revealed a hyper-resonant chest, diminished symmetrical air entry to the lungs, expiratory wheezes and prolongation of the expiratory phase. The heart sounds were rapid and regular with no murmurs. Other physical findings were unremarkable. Arterial blood gases and $\mathrm{pH}$ showed the following values: $\mathrm{pH}$ of $7.45, \mathrm{PO}_{2}$ of $62 \mathrm{~mm} \mathrm{Hg}$ and $\mathrm{PCO}_{2}$ of $30 \mathrm{~mm} \mathrm{Hg}$. Chest roentgenogram showed mild cardiomegaly, and hyperinflation of the lungs with depression of the diaphragms. The electrocardiogram demonstrated sinus tachycardia with a rate of $104 / \mathrm{min}$.

The patient continued to get her previous medications except of prednisone which was replaced by intravenous methylprednisolone $125 \mathrm{mg}$ a day, and she was supplemented with oxygen by nasal cannula. However, no immediate significant improvement was observed in the patient's status. She became more and more anxious with a concomitant deterioration of her asthma, and when the nurse brought her a nebulizer with ipratropium bromide for inhalation, she refused to get the inhalation, destroyed the nebulizer and threw it away, and threw 
herself back on the bed laying down "unresponsive". Soon after that, an abrupt relief of her asthmatic attack was observed, manifested by resolution of the respiratory distress, tachypnea, wheezing and cough, and most of the previous physical findings in the chest examination. Examination of her "unresponsiveness" revealed a typical hysterical attack. Blood gases taken 10 min later, when she still was "unresponsive", showed the following values: a $\mathrm{pH}$ of 7.41, a $\mathrm{PO}_{2}$ of $85 \mathrm{~mm} \mathrm{Hg}$ and $\mathrm{PCO}_{2}$ of $39 \mathrm{~mm} \mathrm{Hg}$. She remained "unresponsive" for about $1 \mathrm{~h}$, then she awakened and again another exacerbation of her asthma began, but was less serious than before, and responded more effectively to the previous treatment with addition of a sedative drug. No other hysterical attacks were observed, she became less anxious, and was discharged after three days in a good status, and was referred for psychological evaluation.

\section{Discussion}

About 200 years ago Theophile Laennec was the first to propose that asthma is a psychosomatic disease [5]. This hypothesis has received increasing support for several decades, so that asthma was considered by some to be a classic example of a psychosomatic disease [6-8]. However, subsequent studies suggested that overt neurotic disorders are not proportionately high in asthmatics, an observation which failed to support the idea that emotion is a common basic cause of this disorder $[9,10]$. Dubo et al [9] found that family psychodynamics was significantly altered by a child with severe, chronic disease but that childhood asthma was not affected in degree of severity by the familial emotional mood. Another study of the personality profiles of asthmatics [11] demonstrated patterns which have been called characteristics of psychosomatic disease, but these patters correlated with the severity of functional impairment rather than presence or absence of asthma. This study could be interpreted as suggesting that emotional disturbances are usually a result rather than a cause of asthma.

It is now well established that emotional factors are so clearly associated with asthmatic attacks, where emotional disturbances could be a trigger and also a result of asthmatic attacks [1-4] as was with our patient. Not surprisingly then, psychiatric interventions such as hypnosis [12-18], or behavioral modifications $[7,19]$ have been reported to produce a favorable response in some subjects with asthma. The extent to which psychological factors participate in the induction and/or continuation of any given acute exacerbation is unknown but probably varies from patient to patient and in the same patient from episode to episode [1].

Paradoxically, very severe stress such as bereavement usually does not worsen, and may even improve, asthma symptoms [1], as occurred in our patient. Although this statement is present in Harrison's Principles of Internal Medicine [1], searching extensively the medical literature by the PubMed and the Medline, we could not find description of any case similar to ours, where the asthmatic attack was precipitated and terminated by the same emotional disturbance, but with different intensities.

The pathways and nature of the interactions between psychological factors and asthma are complex, but have been shown to be operational to some extent in almost half of the patients studies [1]. There are several studies in animals and man which collectively provide strong indirect evidence of a cholinergic vagal pathway by which psychogenic stimuli may affect bronchial hypersensitivity [20-24]. Other pathways could be implicated, such as the non-adrenergic, non-cholinergic bronchodilator system [25], but clear evidence will depend on the development of a specific neural blockers.

In our patient, the interactions between the emotional status and her asthma were very complex and most atypical. From one side, the anxiety was the trigger of her present asthmatic attack. From the other side, as the severity of her asthmatic attack increased, the severity of her anxiety also increased and progressed to a hysterical attack with "unresponsiveness". The hysterical attack ameliorated to a great extent, or even terminated the asthmatic attack almost immediately, such that the respiratory distress, the tachypnea, the diminished air entry to the lungs, the expiratory wheezing and prolongation of expiratory phase, all resolved almost completely, and the arterial blood gases and $\mathrm{pH}$ improved significantly. To the best of our knowledge, no similar case has been reported previously.

The mechanism by which the hysterical attack in our patient ameliorated or terminated the asthmatic attack is not fully understood. Asthma appears to be associated with a characteristic airway inflammatory process [1-3]. Animal experiments show that anterior hypothalamic lesions in small animals affect both immunological and cellular function that could affect inflammation in the airways [1-3, 26]. Similar experiments are not possible in man, but studies of the relationship between the immune and nervous systems indicate that there are a number of ways in which the central nervous system could modulate the degree of airway inflammation in patients with asthma [1-3, 27]. Furthermore, there is anecdotal evidence that patients with severe asthma who suffer hypoxic brain damage have remission of their asthma [28]. In addition, it has become increasingly clear that patients with intense anxiety leading to panic disorders may also have central nervous system biochemical abnormalities [29, 30]. Thus, it may be possible that in our patient, the hysterical attack influenced the immune system through the central nervous system to ameliorate the inflammatory process and the bronchospasm, and consequently the asthmatic attack. Other unknown mechanisms or pathways may also be involved.

\section{Conflict of Interest}

The authors declare no conflict of interest.

\section{Financial Support}

None.

\section{Author Contributions}

All authors certify that they have participated sufficiently in 
the intellectual content. Each author has reviewed the final version of the manuscript and approves it for publication.

\section{References}

1. Barnes PJ. Asthma. In: Kasper DL, Fauci AS, Hauser SL, Longo DL, Jameson JL, Loscalzo J, eds. Harrison's Principles of Internal Medicine. 19th ed. New York: McGrawHill, 2015:1669-1681.

2. Papi A, Brightling C, Pedersen SE, Reddel HK. Asthma. Lancet. 2018;391(10122):783-800.

3. Kang HR, Song HJ, Nam JH, Hong SH, Yang SY, Ju $\mathrm{S}$, Lee SW, et al. Risk factors of asthma exacerbation based on asthma severity: a nationwide populationbased observational study in South Korea. BMJ Open. 2018;8(3):e020825.

4. Van Lieshout RJ, Macqueen GM. Relations between asthma and psychological distress: an old idea revisited. Chem Immunol Allergy. 2012;98:1-13.

5. Keers RY. Laennec: his medical history. Thorax. 1981;36(2):91-94.

6. Gunnarson S. Asthma in children as a psychosomatic disease. Int Arch Allergy Appl Immunol. 1950;1(2):103109.

7. Moore N. Behaviour therapy in bronchial asthma: a controlled study. J Psychosom Res. 1965;9(3):257-276.

8. Luparello T, Lyons HA, Bleecker ER, McFadden ER, Jr. Influences of suggestion on airway reactivity in asthmatic subjects. Psychosom Med. 1968;30(6):819-825.

9. Dubo S, Mc LJ, Ching AY, Wright HL, Kauffman PE, Sheldon JM. A study of relationships between family situation, bronchial asthma, and personal adjustment in children. J Pediatr. 1961;59:402-414.

10. Pinkerton P. Psychosomatic medicine. 3. Psychosomatic aspects of asthma. Practitioner. 1972;208(245):430-436.

11. Heiskell CL, Rhodes JM, Thayer KH. Some psychosomatic aspects of asthma. J Am Med Assoc. 1959;170(15):1764-1767.

12. Diamond HH. Hypnosis in children: complete cure of 40 cases of asthma. Am J Hypn. 1959;1:124-129.

13. Maher-Loughnan GP, Mason AA, Macdonald N, Fry L. Controlled trial of hypnosis in the symptomatic treatment of asthma. Br Med J. 1962;2(5301):371-376.

14. Collison DR. Hypnotherapy in the management of asthma. Am J Hypn. 1968;11:6-11.
15. Maher-Loughnan GP. Hypnosis and autohypnosis for the treatment of asthma. Int J Clin Exp Hypn. 1970;18(1):114.

16. Aronoff GM, Aronoff S, Peck LW. Hypnotherapy in the treatment of bronchial asthma. Ann Allergy. 1975;34(6):356-362.

17. Neinstein LS, Dash J. Hypnosis as an adjunct therapy for asthma: case report. J Adolesc Health Care. 1982;3(1):4548.

18. Ewer TC, Stewart DE. Improvement in bronchial hyper-responsiveness in patients with moderate asthma after treatment with a hypnotic technique: a randomised controlled trial. Br Med J (Clin Res Ed). 1986;293(6555):11291132.

19. Sergeant HG, Yorkston NJ. Verbal desensitisation in the treatment of bronchial asthma. Lancet. 1969;2(7634):1321-1323.

20. Spector S, Luparello TJ, Kopetzky MT, Souhrada J, Kinsman RA. Response of asthmatics to methacholine and suggestion. Am Rev Respir Dis. 1976;113(1):43-50.

21. Richardson JB. Noradrenergic inhibitory innervation of the lung. Lung. 1981;159(6):315-322.

22. Loring SH, Drazen JM, Snapper JR, Ingram RH, Jr. Vagal and aerosol histamine interactions on airway responses in dogs. J Appl Physiol Respir Environ Exerc Physiol. 1978;45(1):40-44.

23. McFadden ER, Jr., Luparello T, Lyons HA, Bleecker E. The mechanism of action of suggestion in the induction of acute asthma attacks. Psychosom Med. 1969;31(2):134143.

24. Rebuck AS, Marcus HI. SCH 1000 in psychogenic asthma. Scand J Respir Dis Suppl. 1979;103:186-191.

25. Barnes PJ. Neural control of human airways in health and disease. Am Rev Respir Dis. 1986;134(6):1289-1314.

26. Van Oosterhout AJ, Nijkamp FP. Anterior hypothalamic lesions influence respiratory airway hyperreactivity. Ann N Y Acad Sci. 1987;496:377-383.

27. Payan DG, McGillis JP, Goetzl EJ. Neuroimmunology. Adv Immunol. 1986;39:299-323.

28. Asthma-what are the important experiments? State of the art/conference summary. Am Rev Respir Dis. 1988;138(3):730-744.

29. Lader M. Behavior and anxiety: physiologic mechanisms. J Clin Psychiatry. 1983;44(11 Pt 2):5-11.

30. Skolnick P, Paul SM. New concepts in the neurobiology of anxiety. J Clin Psychiatry. 1983;44(11 Pt 2):12-20. 